\section{Acute Pancreatitis in the Context of Abdominal Attack of Hereditary Angioedema}

Lourenço $\mathrm{T}^{1}$, Fernandes $\mathrm{M}^{1,2}$, Lopes $\mathrm{A}^{1}$, Pereira Barbosa $\mathrm{M}^{1,3}$ ${ }^{I}$ Serviço de Imunoalergologia, Hospital de Santa Maria, Centro Hospitalar Universitário de Lisboa Norte (CHULN), Lisboa, Portugal

${ }^{2}$ Unidade de Imunoalergologia, Hospital Dr. Nélio Mendonça, SESARAM, EPE, Funchal, Portugal

${ }^{3}$ Clínica Universitária de Imunoalergologia, Faculdade de Medicina, Universidade de Lisboa, Lisboa, Portugal

J Investig Allergol Clin Immunol 2020; Vol. 30(4): 281-283 doi: 10.18176/jiaci.0490

Key words: Hereditary angioedema. Abdominal pain. Pancreatic edema. Pancreatitis. C1 inhibitor.

Palabras clave: Angioedema hereditario. Dolor abdominal. Edema pancreático. Pancreatitis. C1 inhibidor.

Hereditary angioedema (HAE) is a rare autosomal dominant disease (1:50 000 individuals) [1]. The most common forms of HAE result from mutations in the $\mathrm{C} 1$ esterase inhibitor (C1-INH) gene (SERPING1) that lead to a quantitative or qualitative $\mathrm{C} 1-\mathrm{INH}$ deficiency. The 3 types of $\mathrm{C} 1-\mathrm{INH}$ that have been described to date are as follows: C1-INH-HAE type 1 , which is characterized by $\mathrm{C} 1-\mathrm{INH}$ quantitative deficiency; C1-INH-HAE type 2, which is characterized by C1-INH qualitative deficiency; and nl-C1-INH-HAE, which is characterized by normal $\mathrm{C} 1-\mathrm{INH}$ levels and function and is due to a heterogeneous gene mutation that includes FXIIHAE (F12 gene), ANGPT1-HAE (angiopoietin 1), PLG-HAE (plasminogen), KNG1-HAE (kininogen 1), and UNK-HAE (unknown) [1]. Clinically, HAE is characterized by recurrent, nonpruritic edema, which typically involves subcutaneous tissue (face, extremities) and mucosal tissue (oropharyngeal, laryngeal, and gastrointestinal) and may last up to 3-5 days without treatment [1]. Involvement of the upper airways and gastrointestinal system can lead to airway obstruction, asphyxia, and abdominal attack [1,2]. Early diagnosis is therefore fundamental.

Abdominal attack is characterized by abdominal pain with or without other symptoms such as nausea, vomiting, diarrhea, and abdominal distension. These symptoms are secondary to transient edema of the wall of the intestinal tract and fluid shifts into the intestinal lumen or the peritoneal cavity [2]. In rare cases, abdominal attack manifests with signs of pancreatitis. Our aim was to increase physicians' awareness of pancreatitis as a sign or complication of abdominal attack in HAE. We report a case of acute pancreatitis due to abdominal attack of HAE with exclusively pancreatic edema and elevation of pancreatic enzymes in which $\mathrm{C} 1-\mathrm{INH}$ therapy was essential for clinical resolution. A 39-year-old woman with type $2 \mathrm{C} 1$ INH-HAE and a history of multiple episodes of angioedema of the extremities since age 16 years was seen in our Outpatient Department at age 25 years. Her laboratory values were as follows: C3, $140 \mathrm{mg} / \mathrm{dL}$ (90-180); C4, $3 \mathrm{mg} / \mathrm{dL}$ (10-40); C1-INH, $56 \mathrm{mg} / \mathrm{dL}(18-32)$; and functional C1-INH, 30\% (>68). She was initially treated with aminocaproic acid, which partially controlled the angioedema. At age 35 years, she presented with several episodes of abdominal pain and vomiting and started treatment with stanozolol $2 \mathrm{mg} / \mathrm{d}$, which improved her symptoms. At age 39 years, under irregular treatment with stanozolol, she went to the Emergency Department with a new episode of intense and colicky epigastric pain in association with nausea and vomiting. She has no history of alcohol consumption or trauma and was not taking other medications. Abdominal ultrasound revealed a globular and swollen pancreas, with a heterogeneous and hypoechoic structure. There were no other relevant findings, including no free intraperitoneal fluid. C-reactive protein (CRP) had increased by $17.3 \mathrm{mg} / \mathrm{dL}$ and pancreatic enzyme values were elevated (lipase, $512 \mathrm{U} / \mathrm{L}$; amylase, $374 \mathrm{U} / \mathrm{L}$ ). No other analytical changes were recorded (leukocytes, hematocrit, bilirubin, and transaminases). The patient was treated with several analgesics (acetaminophen, butylscopolamine, and tramadol), although her symptoms did not improve. HAE was accepted as being the cause of the acute pancreatitis and, 8 hours after the onset of abdominal attack, $1000 \mathrm{U}$ of $\mathrm{C} 1$ INH concentrate (Berinert, CSL Behring) was administered; her symptoms resolved within about 30 minutes. She was hospitalized for observation without the need for analgesics. After 24 hours, a second abdominal ultrasound scan did not reveal pancreatic changes but did reveal the presence of a moderate amount of free fluid in the Morrison space and in the pouch of Douglas that were not evident in the first scan. CRP and pancreatic enzyme levels had decreased. The patient was discharged 96 hours later; she was asymptomatic and had been diagnosed with abdominal attack of HAE with exclusively pancreatic involvement.

Gastrointestinal tract involvement is one of the most common features of HAE, and attacks affecting the abdomen are almost as common as those affecting the skin $(>90 \%$ of patients) [3]. The difficulty in associating gastrointestinal symptoms with an abdominal attack of HAE often leads to an incorrect diagnosis, such as irritable bowel syndrome or renal colic. Appendicitis, intestinal obstruction, and cholecystitis may be suspected and consequently lead to unnecessary surgical procedures. One study concluded that one third of HAE patients with abdominal symptoms underwent unnecessary abdominal surgeries [2]. In rare cases, abdominal 
Table. Recently Published Cases of Pancreatitis Secondary to Abdominal Attack of Hereditary Angioedema (Adapted From Lopes-Veronez et al, Front Med (Lausanne). 2019;6:80

\begin{tabular}{|c|c|c|c|c|c|c|}
\hline Paper & $\begin{array}{l}\text { Gender, } \\
\text { Age }\end{array}$ & $\begin{array}{l}\text { Lipase, } \\
\text { U/L }\end{array}$ & $\begin{array}{l}\text { Amylase, } \\
\text { U/L }\end{array}$ & Treatment & $\begin{array}{c}\text { Clinical } \\
\text { Evaluation }\end{array}$ & $\begin{array}{c}\text { Gastrointestinal } \\
\text { Surgeries }\end{array}$ \\
\hline Our case & F, 39 & 512 & 374 & C1 inhibitor & Improvement in $30 \mathrm{~min}$ & No history \\
\hline Lopez-Veronez et al [3] & $\begin{array}{c}\mathrm{M}, 21 \\
\mathrm{~F}, 47\end{array}$ & $\begin{array}{l}1.159 \\
\mathrm{ND}\end{array}$ & $\begin{array}{l}292 \\
210\end{array}$ & $\begin{array}{l}\text { Icatibant } \\
\text { Icatibant }\end{array}$ & $\begin{array}{l}\text { Improvement in } 3 \mathrm{~h} \\
\text { Improvement in } 1 \mathrm{~h}\end{array}$ & $\begin{array}{c}\text { No history } \\
\text { Appendectomy }\end{array}$ \\
\hline Loudin et al [4] & F, 56 & 663 & ND & C1 inhibitor & Improvement in $30 \mathrm{~min}$ & Cholecystectomy \\
\hline Maamer et al [5] & F, 73 & 1235 & 869 & Danazol & Improvement in $5 \mathrm{~d}$ & No history \\
\hline Czaller et al [6] & F, 29 & 1452 & 2615 & $\mathrm{C} 1$ inhibitor (2 times) & Improvement in $4 \mathrm{~h}$ & Appendectomy \\
\hline Cancian et al [7] & $\mathrm{F}, 32$ & ND & 470 & C1 inhibitor & Improvement in $30 \mathrm{~min}$ & ND \\
\hline
\end{tabular}

Abbreviations: F, female; M, male; ND, not determined.

attacks of HAE are associated with acute pancreatitis. Although this association is not fully documented, it is thought that pancreatic edema may cause obstruction of the pancreatic duct or the ampulla of Vater, leading to episodes of pancreatitis [3]. The Table shows several published cases [3-8] of acute pancreatitis due to abdominal attack of HAE. All patients were treated with specific HAE therapy, and symptoms improved. This improvement was faster in patients undergoing treatment of an acute attack.

The unspecific symptoms of abdominal attack of HAE can hamper diagnosis and, in the absence of clinical suspicion, treatment may be postponed altogether. In addition, laboratory parameters remain largely unchanged, except for an increase in hematocrit, which is probably secondary to hemoconcentration, dehydration, and translocation of fluid into the intestinal wall, as well as leukocytosis [9]. A recent study [10] found a correlation between CRP levels and abdominal attack of HAE: increased CRP levels during the attack are found mainly in patients with abdominal locations. In the absence of an attack, increased CRP levels may alert the physician to severe inflammation. Imaging may prove useful in the initial investigation of abdominal pain episodes. During an abdominal attack, endoscopy may show ascites and/or visceral edema and frequently edema of the intestinal wall [2]. Since intestinal swelling associated with acute HAE attacks could induce pancreatitis, serum amylase and lipase should be monitored, as management of the attack could vary depending on the results.

The therapies currently available for treatment of $\mathrm{HAE}$ attacks comprise $\mathrm{C} 1-\mathrm{INH}$ concentrate, hr-C1-INH, icatibant, and ecallantide [1]. As no specific biomarker of this condition has been identified, rapid improvement in symptoms after administration of specific therapy enables us to differentiate between abdominal attacks of HAE and other etiologies.

Although rare, HAE is associated with significant comorbidity, and a history of unnecessary abdominal surgeries is not unusual in abdominal attack of HAE. Health professionals should be aware of the existence of this entity to perform early diagnosis and institute appropriate therapy. Since HAE is a potential cause of acute abdomen (eg, acute pancreatitis), HAE-specific therapy should be considered a therapeutic option.

\section{Funding}

The authors declare that no funding was received for the present study.

\section{Conflicts of Interest}

The authors declare that they have no conflicts of interest.

\section{Previous Presentations}

The results of this study were presented in a poster at the $38^{\mathrm{a}}$ Reunião Anual da Sociedade Portuguesa de Alergologia e Imunologia Clínica 2017, Lisbon, and at the 2018 EAACI Congress in Munich.

\section{References}

1. Maurer M, Magerl $M$, Ansotegui I, Aygören-Pürsün $E$, Betschel $\mathrm{S}$, Bork K, et al. The international WAO/EAACI guideline for the management of hereditary angioedema - The 2017 revision and update. Allergy. 2018;73:1575-96.

2. Koruth JS, Eckardt AJ, Levey JM. Hereditary angioedema involving the colon: endoscopic appearance and review of Gl manifestations. Gastrointestinal Endoscopy. 2005;61:907-11.

3. Moreno AS, Maia LSM, Palhas PB, Dias MM, Muglia VF, Castelli EC, et al. J Investig Allergol Clin Immunol. 2016;26:57-9.

4. Lopes-Veronez $C$, Albuquerque Campos R, Constantino-Silva RN, Nicolicht P, Pesquero JB, Grumach AS. Associated acute pancreatitis in C1-inhibitor deficient and normal C1-Inhibitor patient: Case Reports and literature review. Front Med (Lausanne). 2019;6:80.

5. Loudin M, Modiano N, Sallay S. Rapid improvement of pancreatitis secondary to hereditary angioedema with C1 inhibitor administration. Am J Med. 2016;129:75-6.

6. Ben Maamer A, Zaafouri H, Haoues N, Cherif A. Acute pancreatitis due to hereditary angioedema. Tunis Med. 2011:89:579-80.

7. Czaller I, Molnár K, Csuka D, Varga L, Farkas H. Successful outcome using C1-inhibitor concentrate in acute pancreatitis caused by hereditary angioedema. Gastroenterol Nurs. 2011;34:60-3. 
8. Cancian M, Vettore G, Realdi G. An uncommon cause of acute pancreatitis. Hereditary angioedema-induced acute pancreatitis. Gastroenterology. 2011;140:33-370.

9. Ohsawa I, Nagamachi S, Suzuki H, Honda D, Sato N, Ohi H, et al. Leukocytosis and high hematocrit levels during abdominal attacks of hereditary angioedema. BMC Gastroenterology. 2013;13:123.

10. Hofman ZLM, Relan A, Hack EC. C-reactive protein levels in hereditary angioedema. Clin Exp Immunol. 2014;177:280-6.

I Manuscript received November 4, 2019; accepted for publication January 24, 2020.

\section{Tatiana Lourenço}

Serviço de Imunoalergologia, Hospital de Santa Maria, Centro Hospitalar Universitário de Lisboa Norte (CHULN) Avenida Prof. Egas Moniz s/n 1649-035 Lisboa, Portugal E-mail: tatiana-lourenco@live.com.pt 